\title{
EL MITO DARWINISTA EN EL AULA DE CLASE: UN ANÁLISIS DE FUENTES DE INFORMACIÓN AL GRAN PÚBLICO
}

\author{
The Darwinist myth in clasroom: an analysis of information \\ sources for public understanding
}

\author{
Nelio Bizzol \\ Adela Molina ${ }^{2}$
}

\begin{abstract}
Resumo: Este artigo tem como objetivo analisar como certas fontes secundárias de informação sobre Darwinismo apresentam conceitos centrais da teoria. Essa análise é considerada importante para o contexto educacional, uma vez que fontes primárias de informação raramente são utilizadas com esse propósito. O livro de Huxley e Kettlewell "Darwin and his World" foi estudado, bem como o livro de Richard Dawkins "O Relojoeiro Cego". Estes dois livros têm sido referências muito importantes para professores e estudantes. Este artigo mostra algumas distorçôes de alguns conceitos, bem como de evidências factuais sobre a cronologia da construção da teoria.
\end{abstract}

Unitermos: ensino de evolução, Darwinismo, História da Ciência, fontes secundárias.

Abstract: This article aims at analyzing how secondary sources of information of Darwinism present key-concepts of the theory. This analysis is considered important for educational purposes as primary sources rarely are used. Huxley and Kettlewell's book, "Darwin and His World" was studied, as well as Richard Dawkins' "The Blind Watchmaker". These two books have been major references for teachers and students. This article shows how distorted some concepts are, as well as some factual evidence about the chronology of the construction of the theory.

Keywords: teaching of evolution, Darwinism, History of Science, secondary sources.

Los textos escolares de biología tradicionalmente abordan el tema de la "Evolución" de una forma muy particular. A diferencia de otros tópicos disciplinares, la vida del científico y los métodos utilizados para conseguir resultados, ganan considerable relevancia. Lo anterior, es justificado por sus objetivos. Se pretende que la enseñanza de este tópico tenga como efecto propiciar la comprensión de los estudiantes sobre lo que es la ciencia y el trabajo de los científicos, junto con los objetivos directamente relacionados con los conocimientos de las teorías evolutivas y sus implicaciones biológicas.

Es el caso de la imagen pública de Charles Darwin y la de su trabajo, presentes en los manuales escolares de Biología de diferentes países del mundo, en las cuales, ciertamente se reconoce la influencia de obras de divulgación científica relacionadas con el trabajo realizado por el naturalista inglés.

De este modo, este artículo hace parte de un proyecto que se propone dar mayor comprensión a la forma como el darwinismo es presentado en el aula de clase, específicamente en los textos escolares. En un artículo anterior, Bizzo (1994) señaló la importancia de estudios de tipo sociológico para establecer los objetivos implícitos en el uso de diferentes versiones del darwinismo en la escuela, en especial en el período de la llamada "guerra fría". Estudios a partir de obras de especialistas en la historia del darwinismo y de escritos originales permitieron identificar dos corrientes básicas descritas como "aproximación Baconiana" y como "aproximación crítica" (Bizzo 1997).

\footnotetext{
${ }^{1}$ Faculdade de Educação - Universidade de São Paulo - Brasil

${ }^{2}$ Universidad Distrital "Fancisco José de Caldas" - Bogotá - Colômbia
} 
La primera fue identificada en los trabajos de E, Radl y E, Mayr y la segunda en los de John C Greene y Robert Maxwell Young. Otros autores importantes, por supuesto, pueden ser agregados a estas categorías así como también otras podrían ser creadas. Ahora, nos interesa estudiar la forma como esta diversidad de interpretaciones es presentada al público en general, lo que ciertamente, tiene repercusiones en el contexto escolar.

Como en el trabajo de Bizzo (1997) nos basaremos en el estudio de fuentes bibliográficas de relevancia en el tema. Dentro de la gran cantidad de escritos, de divulgación, referidos a Darwin, podemos destacar, en un pasado reciente, los nombres de Julian Huxley, H.M.D. Kettlewell y, en el presente el de Richard Dawkins. Así sea ésta una elección arbitraria, se justifica por el hecho de ser ellos científicos respetados por sus pares en el campo específico de la biología evolutiva, que han realizado estudios y descubrimientos de gran repercusión y, además de esto, han escrito obras de divulgación de gran suceso editorial. Su efecto en los textos escolares es muy evidente. La obra de Huxley y Kettlewell, Charles Darwin and his world tuvo, sin duda, gran influencia sobre los textos escolares escritos en los años sesenta. Dawkins, con El Gen Egoísta y, mas recientemente, The Blind Watchmaker, influencio los textos norteamericanos del final de los 80 y no dejó de repercutir en los que se produjeron en la década del 90.

\section{El mundo que no era solamente de Darwin}

El libro de Huxley y Kettlewell ${ }^{3}$ es, sin duda, muy importante en la reconstrucción de la historia del darvinismo, con relación, a su transito desde el ámbito científico hacia el educativo. Se trata, como ya anotamos antes, de una obra escrita por dos autores reconocidos en el área; inclusive uno de ellos ligado, por vínculos consanguíneos, con uno de los protagonistas de mayor notoriedad en los debates que se sucedieron después de la publicación del "Origen de las Especies", en 1859. Es así como, Sir Julian Huxley es nieto de Thomas Henry Huxley, el "bulldog de Darwin”. De otra parte, Kettlewell alcanzó fama mundial por sus investigaciones en melanismo industrial de las mariposas de la región de Merseyside en noroeste de Inglaterra.

En consecuencia de la gran importancia dada a sus puntos de vista personales, los autores no tienen en cuenta otros reconocidos estudios. Es así como, el libro no proporciona ninguna referencia bibliográfica en las cuales sustentar las afirmaciones que presenta y, tampoco indicaciones sobre la bibliografía consultada. Se da a entender, que el libro se basa apenas en material original cedido por Lady Barlow, nieta de Charles Darwin.

Combinando material iconográfico de primera mano, afirmaciones taxativas, grande autoridad intelectual y ausencia de referencias bibliográficas, el resultado inspira preocupación. Ya que, las afirmaciones presentes en el libro no dejan ninguna duda y dan muy poca atención a cualquier opinión que no se identifique totalmente con las ideas de los propios autores. El hermetismo de la argumentación acaba por dar la impresión al lector que aquellas son opiniones unánimes e incuestionables.

Por ejemplo, en dicho libro, se hace una de las defensas mas ardorosas a la tesis de que los problemas de salud enfrentados por Darwin fuesen debidos a una supuesta enfermedad tropical (mal de Chagas), contraída en Chile, la cual, es una posibilidad admitida por pocos especialistas. Tanto el conocimiento de la enfermedad como la vida de Darwin llevan a otra conclusión. Entre otras razones los síntomas relatados por Darwin - muy diferentes al mal de Chagas- ya eran sentidos antes de su viaje alrededor del mundo. A pesar de ello, Huxley y Kettlewell llegaron a incluir un ataque de benchugos como uno de los episodios más importantes de su vida, inclusive

${ }^{3}$ Huxley, Julian and H. B. D. Kettlewell. Charles Darwin and his world. Book Club Associates, sll, (1975). 
El mito darwinista en el aula...

con una fecha precisa. Escribieron: "También tenemos certeza que Darwin tuvo problemas con benchugos en Chile. Posteriormente (26 de Marzo de 1835) en su expedición a Mendoza, escribió...". ${ }^{4}$

El libro posee un carácter biográfico, que procura mostrar la vida del científico como si ella fuese sido enteramente inclinada a la elaboración de una teoría. El recorrido de las teorías darwinistas se confunde, en el libro, con la trayectoria de la vida personal de Charles Darwin. La perspectiva individual adquiere una gran dimensión frente a otras, como la social, política, etc. En otras palabras, la construcción de las teorías darwinistas es presentada como un hecho ahistórico.

Aunque no se pueda afirmar, que ciertas aseveraciones erróneas hayan, surgido por primera vez con la publicación de esta obra, sin embargo, no existe duda que ella les dio resonancia.

Así, en la página 74 se observa, por ejemplo, la siguiente afirmación:

La primera edición de 1250 copias al precio de quince shillings fue vendida toda en el día del lanzamiento. ${ }^{5}$ Una segunda edición fue sacada seis semanas después, y desde entonces una secuencia de nuevas ediciones revisadas, tuvieron que ser preparadas, con el fin de no interrumpir las ventas.

Estas líneas fueron publicadas seis años después del meticuloso levantamiento hecho por Morse Peckhan ${ }^{6}$, que culminó con la edición del Variorum Text, una compilación de todas las ediciones del Origen de las Especies durante la vida de Darwin, anotando, cuidadosamente, cada modificación realizada en cada frase. El relato de Peckhan, seguramente de conocimiento de Sir Julian Huxley y Kettlewell, es inequívoco pero ignorado por ellos.

John Murray, el editor, preparaba para noviembre el lanzamiento de otoño de 21 obras. Fue realizada una campaña publicitaria en los meses anteriores principalmente en el Athenaeum, un periódico literario. El libro de Darwin era el tercero de la larga lista. El primero era "La narrativa de M'Clintock del descubrimiento del paradero de Sir Jonh Franklin".

El trabajo de Darwin ya venía siendo noticia desde septiembre. Charles Lyell lo anunció en una reunión de la Sociedad Geológica, que contaba con la presencia del príncipe consorte. El anuncio fue publicado en la revista El Athenaeum el día 24 de septiembre de 1859.

El libro continuó siendo objeto de propaganda, con cierta notoriedad con respecto a los demás hasta el punto que, en la edición del día 19 de noviembre de 1859, el editor del periódico, W.N. Dixon, reservó el artículo principal, de cinco columnas, a una reseña del libro. Escribió Peckman, ' "La reseña era tan específicamente ajustada para despertar el interés y estuvo tan bien calculada para las ventas al por mayor, que sino fuese por la reputación del periódico, se podría suponer que por detrás de ella, estaba la mano de John Murray”. Ella provocaba controversia sobre cual sería el papel de Dios sí se admitiese que el Hombre descendía del Mono. El autor de tal reseña también adelantaba detalles de la salud de Darwin, dando la impresión que con ello se privaba de su amistad.

El sistema de comercialización de libros de la época, consistía en una feria para libreros, que compraban y pagaban por los libros. Después se hacía la entrega y solamente, a partir de ese momento, se realizaba la venta al público. Los registros de John Murray, publicados en el Athenaum del 26 de noviembre, dan cuenta que en esta feria, al por mayor, realizada en el día 26 de noviembre de 1859, en su orden los libros más vendidos fueron los siguientes: el

\footnotetext{
${ }^{4}$ Huxley \& Kettlewell citan la fecha de 26 Marzo de 1835, cuando Darwin estaba a "cuatro leguas" al sur de la cuidad de Mendoza, por lo tanto el episodio narrado sucedió realmente en Argentina. En Chile también realizó experimentos con benchugos, observando la longevidad de adultos alimentados con la sangre humana.

5 "Was bought up on the day of the publication", en el original. La fecha tradicionalmente atribuida es 19 de noviembre de 1859. Más adelante son presentadas evidencias de no ser correcta.

${ }^{6}$ Peckan, Morse. The Origin of Species by Charles Darwin: a variorum text. Philadelphia, University of Pennsylvania Press, (1959).
}

${ }^{7}$ Peckman, M. 1959, (citado), Pág.16. 
libro sobre Sir Franklin, ${ }^{8} 7600$ copias; Self Help de Samuel Smile, 3200 copias; The life and Letters of Sir Fowell Buxton, abolicionist, 2500 copias; A life of Rev. Daniel Wilson, 2200 copias; y Origin of Species, 1500 copias vendidas. Como existían 1192 volúmenes disponibles, ${ }^{9}$ todo conduce a creer que el editor tenía vendidas más copias de lo que poseía. Se puede comprender así, la razón de un nuevo tiraje, inmediatamente después, con la intención de corregir el tamaño del primero. ${ }^{10}$

Así, concluyó Morse Peckham: "Sí ese relato fuese correcto, y no existe una razón para dudar de eso, la afirmación tan común de que la primera edición fue toda vendida en el primer día -que muchos entendieron se refería a la compra de lectores en librerías - tiene que ser revisada". ${ }^{.1}$

El día del lanzamiento del libro (en las librerías) también es objeto de controversia, una vez que Darwin afirmaba haber sido el día 24 y los anuncios del editor mencionaban el día 26. Cuando Darwin estableció esta fecha, lo hizo con la seguridad de que su libro se vendería profusamente, probablemente cuando escribió a Lyell, que se realizara el lanzamiento, solamente en el momento en que se percibiera que su libro iría tener una buena acogida ${ }^{2}$ ), por ello, es posible que se haya equivocado. Peckham afirma que el libro fue puesto a la venta el día 26 de noviembre.

De cualquier forma, la afirmación presente en el libro de Sir Julian Huxley y Kettlewell trascendió a los textos escolares y medios masivos de comunicación, haciendo eco hasta hoy; por el contrario, los hechos y evidencias en contra de ella son muy poco conocidos. Sin embargo, en los medios académicos, la versión de Peckham no deja dudas.

El segundo lote de libros, que según Huxley y Kettlewell, salió seis semanas después, ${ }^{13}$ realmente pudo haber sido puesto en venta (por lo menos en depósito) aún antes de este tiempo. Las pequeñas correcciones hechas por Darwin fueron terminadas a mediados de diciembre. El periódico The Times del 26 de diciembre, incluía una propaganda del libro, donde era anunciado el lanzamiento del nuevo tiraje, diciendo estar a la venta "el quinto millar". Así nadie se atrevía

\footnotetext{
${ }^{8}$ La expedición ártica de Sir John Franklin fue la primera con navios movidos a vapor y una serie de otras innovaciones revolucionarias para la época (llegando a inaudita sofisticación, de poseer agua caliente en los aposentos de los oficiales, por ejemplo). A pesar de su avance tecnológico, la expedición desapareció en el año 1847 intentando en el paso norte, el camino ártico, entre el Atlántico y el Pacífico. La expedición del capitán M'Clintock, recién llegada, habia encontrado los diarios a bordo de los navios HMS Erebus y HMS Terror, abandonados por la tripulación. Cuando los sobrevivientes dejan los barcos, Sir John Franklin ya habia muerto (el diario indica la fecha del 11 de junio de 1847), en un número de 105 y en una desesperada caminata rumbo al sur, terminaron muriendo de escorbuto, hambre y frio. Apenas tres cuerpos fueron hallados por la expedición de M'Clintock, que dio a todos los demás, por desaparecidos. Una de las dudas que envolvían su relato, era al respecto, de la posibilidad de sobrevivientes viviendo con los esquimales, lo que el capitán hallaba absolutamente imposible. Pero el mayor interés era por la localización de los barcos. La esposa de Franklin habia dotado a los comandantes con un mapa misterioso, supuestamente diseñado con el auxilio de una niña Irlandesa de cuatro años, Wessey Copin, que muriera poco antes. Consta que el mapa indicaba con precisión el lugar de la muerte de Franklin. No era dificil imaginar, entonces, las razones de tanto interés por este libro. En el libro de M'Clintock no se encuentra ninguna referencia a la supuesta previsión de la niña Irlandesa. El prefacio del livro fuera escrito por Roderick Impey Murchison (1792-1871), presidente de la Royal Geografical Society, importante opositor de las ideas evolucionistas, que acreditaba ser la "explosión cámbrica" una prueba irrefutable del momento de la creación divina (Gould, 1989: 56). Escribió Darwin: "To the question why we do not find records of these vast primordial periods, I can give no satisfactory answer. Several of the most eminent geologists, with Sir R. Murchison at their head, are convinced that we see in the organic remains of the lowest Silurian stratum the dawn of life on this planet. Other highly competent judges, as Lyell and the late E. Forbes, dispute this conclusion." (Darwin, 1859:307). El Bajo Siluriano correspondia a lo que hoy llamamos Cambriano, o sea el periodo entre 545 y 505 m.a.

${ }^{9}$ Morse Peckham afirma que los libros contables de John Murray, el editor, indican un emisión de 1250 ejemplares, siendo sido destinados a la divulgación 58 .

${ }^{10}$ Ese sería inclusive el motivo de -técnicamente- ser incorrecto hablar de una "segunda edición" de 1860. Tratase, eso sí, de una "Reimpresión". La primera persona, que cometió dicho equivoco, fue el propio Darwin.

${ }^{11}$ Morse Penkham, 1959, utilizó la expresión "must be revised", afirmación de tipo imperativa; (citado) Pág. 17.

${ }^{12}$ Darwin-Lyell, Downe, 14-01-1860, Darwin Papers, Manuscripts Room, Cambridge University Library, Cambridge.

${ }^{13}$ Ellos tomaron el registro de Darwin, 7 de enero, como la fecha del lanzamiento de la "segunda edición" que como ya se dijo en realidad se trataba de una reimpresión.
} 
a admitir que el profesionalismo del editor estuviese de nuevo detrás de la iniciativa, una nueva reseña favorable acompañaba la propaganda, solo que esta vez ella estaba firmada; se trataba nada menos que de Thomas Henry Huxley que ya en aquella época un zoólogo respetado. Peckham cree que la "segunda edición" comenzó llegar a las librerías el mismo día 26, en una perfecta sincronía entre las piezas, reseñas, proceso de producción y distribución.

La "tercera edición" saldría a fines de abril de 1861, 16 meses después, con una emisión de 2000 ejemplares. El libro solo fue reimpreso por John Murray casi seis años después, en diciembre de 1866 y apenas 1500 ejemplares.

Estas cifras indican la exageración de la afirmación de Huxley y Kettlewell, según la cual, el libro había sido un best seller. Además, de ser un libro eminentemente técnico y sin citas y referencias bibliográficas, ${ }^{14}$ no se podía esperar un éxito similar al de los "thrillers". Por otra parte, fue justamente el modesto desempeño de las ventas que condujo al editor sugerir a Darwin que no insistiese en la edición de la versión extensa, y aún inacabada, del libro y que buscase la producción de otros volúmenes de asuntos relacionados. ${ }^{15}$

Es extraño que el "suceso" editorial del "Origen de las especies" sea citado recurrentemente y utilizado de la misma manera en el contexto educativo. Si esto no corresponde a la verdad, como bien lo sabían Huxley y Kettlewell, ¿`cuál es la razón entonces para reiterar este "hecho"?. Todos sabemos que los Principia Mathematica de Newton, por ejemplo, no fue un best-seller y, sin embargo eso no descalificó su contenido.

Otra afirmación, que parece haber tenido el misma comportamiento, se refiere a que Karl Marx había ofrecido la dedicatoria de la traducción de El Capital a Darwin. Al respecto, en palabras poco comedidas, Huxley y Kettlewell, en plena "Guerra Fría”, escribieron:

Karl Marx veneraba a Darwin y quería dedicarle la traducción Inglesa de "El Capital", un pedido que fue educadamente rechazado. Darwin se convirtió en un héroe intelectual de la Unión Soviética. ${ }^{16}$

En este caso, estamos en una situación diferente de la anterior, una vez que esta versión no estaba en duda por la época de la publicación del libro. Hasta hace pocos años atrás los historiadores daban crédito a la veracidad de dicha afirmación, a pesar del inmenso volumen de evidencias en contra de ella. Todo indica que ella estaba basada en dos hechos.

Darwin poseía el volumen I del libro de Marx, ejemplar que el propio Marx le remitió en junio de 1873. La dedicatoria dice: "Sr. Charles Darwin, de parte de su sincero admirador, Karl Marx, Londres, 16 de junio de 1873.” Sigue una dirección.

Tal vez esa dedicatoria sea la justificación del uso del verbo "venerar", utilizado por Huxley y Kettlewell para describir los sentimientos de Marx hacia Darwin. Además, queda la impresión de que el foco de la relación entre ellos, haya sido la principal obra de Marx. Como vemos, es fácil comprender el origen de la versión sobre la oferta de la dedicatoria, pero lo mismo no se puede decir del resto de la historia.

Otro hecho, se refiere a la existencia de una carta en el archivo de Darwin, con fecha del 13 de octubre de 1880, donde se le ofrece la dedicatoria de una obra adjunta a dicha nota. La segunda página de la carta, que posiblemente contenía la firma del remitente, no es conocida. De esta forma, se trata de una carta sin remitente, donde tampoco figura el nombre de la obra en cuestión. ${ }^{17}$

\footnotetext{
14 Staufer, 1975, con mucha razón, supone que la falta de citas y referencias bibliográficas se haya debido al corto espacio de tiempo disponible que tuvo Darwin para preparar la publicación. Según él, la inclusión de todas las referencias bibliográficas habría atrasado por lo menos un año.

15 Peckham, 1959, (citado), pag 18.

${ }^{16}$ Huxley y Kettlewell, 1975 (citado), Pág. 80.

${ }^{17}$ Darwin Papers, Cambridge University Library, Manuscripts Room.
} 
Darwin respondió a la oferta. Todo indica que él no conocía la obra y no existen indicios para suponer que se tratara de algún tipo de traducción. Es también verdad que Darwin no abrió el libro que Marx le había enviado ocho años antes. Ese ejemplar se encuentra en el Museo de Darwin, en Downe (Kent), y puede ser visto aún con las hojas sin cortar. ${ }^{18}$ Pero en la carta de agradecimiento enviada a Marx el primero de octubre de 1880, Darwin daba la impresión de haber leído el libro, calificándolo de "gran obra". Sin embargo, si se tratara nuevamente de El Capital, Darwin debería haber hecho alguna alusión a la opinión expresada anteriormente.

En esta carta de respuesta no existía destinatario, es probable que su nombre se encontrará solo en el sobre, de lo cual no se sabe más. El contenido de la carta dice que a él (Darwin) no le gustaría ver su nombre envuelto en críticas a la religión, que ese asunto prefería que se dejara a criterio de cada persona, que cada uno decida sobre su fe de forma independiente. Tal vez esa afirmación haya servido de pretexto para que se pensase que el destinatario fuese Marx. ${ }^{19}$

Sería muy difícil establecer con precisión quien fue el que inventó la versión de la oferta de la dedicatoria. No existen evidencias de que hubiese sido el hijo de Darwin, Francis, quien organizó la edición de su correspondencia personal, donde no se encuentra referencia a este "hecho". En el caso, en que esto hubiese sido así, ciertamente sería de su conocimiento, y lo habría consignado en el libro de correspondencia de Darwin. Esto porque él hubiese recurrido a sus recuerdos y comentarios escuchados de su padre. Es casi seguro que el origen de esa versión sea el producto de un análisis aislado de la correspondencia personal de Darwin, realizado después de la Revolución Bolchevique. De hecho, James Moore (comunicación personal a N. Bizzo) cree que esta versión fantasiosa circuló por primera vez en un "panfleto izquierdista” por los años de 1920's en Inglaterra.

Una sucesión de artículos publicados en revistas especializadas discutirían el asunto. En 1974 la correspondencia entre Darwin y Marx estaba fuera de toda duda. Ralph Colp Jr, al escoger material para su libro sobre la enfermedad de Darwin, examinó su correspondencia personal y escribió un artículo sobre las relaciones de estos dos pensadores. ${ }^{20}$

La primera tentativa de probar que la correspondencia entre Marx y Darwin era falsa, partió paradójicamente de una sospecha infundada. Lewis Freuer, impulsado por el artículo de Ralph Colp Jr, publicó en 1975 un artículo ${ }^{21}$ donde decía que la carta de respuesta de Darwin a Marx donde él rechazaba la oferta de la dedicatoria, podría ser falsa, una vez que el timbre del papel no era el usual. Inicialmente él levantó la sospecha que, probablemente, esa carta hubiese sido falsificada por Edward Aveling, el controvertido yerno de Marx. En esa época Aveling hacía parte de un grupo con intensa actividad política, incluso parlamentaria y estaba por publicar un libro sobre Darwin. Freuer perfeccionaba la idea que, probablemente, la dedicatoria ofrecida en la carta dirigida a Darwin fuese justamente de dicho libro de Aveling ("The Student's Darwin"), y no de Marx.

Entonces, la carta de respuesta de Darwin, rechazando la oferta, fue sometida a un examen grafológico, por uno de los dos mejores especialistas en la caligrafía de Charles Darwin. La conclusión aparece publicada en un nuevo artículo de Ralph Colp Jr. ${ }^{22}$ En ese artículo se presenta el resultado del examen, quedando fuera de duda la autenticidad de Darwin, como el autor de la carta de rechazo a la dedicatoria. A pesar de ello, Ralph Colp Jr, reconoce que no existe ninguna evidencia de que el remitente de la carta original, hubiese sido realmente de Marx. Dicho autor insiste en que el remitente debió haber sido Edward Aveling.

\footnotetext{
${ }^{18}$ Se sabe, que esa era una tradición de los editores de la época, para evitar que el libro fuese leido en los estantes de las librerías

${ }^{19}$ Lo que no deja de ser irónico, una vez que el materialismo es -por excelencia-una invención burguesa.

${ }^{20}$ Colp Jr. The contacs between Karl Marx y Chales Darwin. Journal of the History of Ideas, 35: 329-338 (1974).

${ }^{21}$ Freuer, L. Is the "Darwin-Marx" correspondence authentic? Annals of Science 32:1-12 (1975).

${ }^{22}$ Colp Jr, R. The contacts of Chales Darwin with Edward Aveling and Karl Marx. Annals of Science, 33: $387-394$ (1976).
} 
El asunto se retomó nuevamente, en un artículo de $1979,{ }^{23}$ donde el problema de la autenticidad de las autorías sería establecido de forma convincente. En ese artículo Marx, oficialmente, dejó de ofrecer la dedicatoria de El Capital a Darwin. ${ }^{24}$

La importancia de este pasaje, no radica propiamente en su inexactitud factual. La verdad, el posee un significado simbólico muy profundo que le confiere un carácter alegórico. Se trata de la imagen de un gran científico, dueño de una gran obra, reconocido en su superioridad por un pensador menor, que tuvo que aproximarse a él para rendirle pleitesía, sin éxito alguno. En la época de mayor repercusión social de dicha alegoría, el período de la guerra fría, ella tuvo una aplicación inmediata. El enfrentamiento este-oeste, dos sistemas socio-políticoeconómicos en confrontación, en disputa por la dominación planetaria, configuraban, sin duda, el fondo de esta alegoría. El hecho de haber sido transpuesta al aula, en diferentes países, es algo que debería ser analizado con más detenimiento en el futuro. Muy seguramente, millones de jóvenes de todas partes del mundo, fueron sometidos a esta influencia.

Otro ejemplo muy ilustrativo de la forma como se expone el trabajo del científico, puede ser apreciado en otro pasaje, de contenido altamente significativo. En la presentación del trabajo de Darwin, con las líneas paralelas de Glen Roy, en Escocia, se pone en evidencia la intención de los autores, en mostrar de una forma determinada la vida de este científico.

El trabajo de Darwin en Glen Roy, en 1839, fue una de sus más problemáticas incursiones en la geología. Al contrario de las anteriores, la admisión de mecanismos elevadores del terreno para explicar el paisaje actual, como lo apreciaría Lyell, le produjo amargos frutos. Darwin procuró explicar la existencia de líneas esculpidas en las colinas de ese lugar; diciendo que se produjeron primero las líneas, por la acción de la erosión marina, y posteriormente las montañas por elevación del terreno.

Según Rudwick, $1974^{25}$

\begin{abstract}
Existe fuerte evidencia de que Darwin estaba predispuesto a interpretar las lineas paralelas de Glenn Roy como playas marinas, debido a que su experiencia anterior con las líneas paralelas de Coquimbo 24 y otras marcas a nivel del mar más elevadas en Chile. Ciertamente sus notas, en sus cuadernos de campo, revelan una inclinación de ver las marcas de Lochaber, como señales de niveles más elevados del mar. Y no existe nada sorprendente y especial en ello.
\end{abstract}

Darwin publicó sus conclusiones, de tal forma, que ellas quedaran enunciadas desde el título mismo ${ }^{27}$. Dicho artículo había sido evaluado favorablemente por su profesor de geología en Cambridge, Sedgwick. Éste sería el único artículo que Darwin publicaría a través de la Royal Society. Es claro que, Darwin pretendía que este trabajo fuese la continuación de otro anterior recién publicado, aprovechando su prestigio en la Geological Society (Bizzo, 2002). La corta publicación se llamaba On the connection of certain volcanic phenomena and on formation of mountain chains and volcanos as the effects of continental elevations. ${ }^{28}$

\footnotetext{
${ }^{23}$ Fay, M. A. Did Marx offer to dedicate Capital to Darwin?. Journal of History of Ideas, 39: 133-46 (1979).

${ }^{24}$ Asi el artículo haya sido publicado en una fecha posterior, se le atribuye este descubrimiento a Fay M. A, que estuvo imposibilitada, por problemas de salud, a publicar los articulos en fecha anterior y a Ralph Colp Jr.

${ }_{25}$ Rudwick, M. S. J. Darwin and Glenn Roy: A Great Failure in scientific method?. Studies in the History and Philosophy of Science, 5: 97-185 (1974).

${ }^{26}$ El texto se refiere a sus trabajos geológicos realizados en Chile durante la expedición del Beagle. Como es bien sabido, Darwin utilizaba el libro Lyell como referencia, en la época de sus investigaciones geológicas.

${ }^{27}$ Darwin, C.R. Observations on the parallel roads of Glen Roy, and of other parts of Lochaber, with an attempt to prove that they are of marine origen. Philosophical Transactions of the Royal Society, vol 1839: 39-81

${ }^{28}$ Darwin, C.R. On the connection of certain volcanic phenomena and on formation of mountain chains and volcanos as the effects of continental elevations. Proccedings of the Geological Society of the London, 2 (56): 654-660 (1838).
} 
Su tesis no explicaba la total inexistencia de fósiles marinos, lo que era de esperarse, ni las marcas encontradas en las rocas, típicas de la acción de los glaciares. Luego, después de la publicación de sus conclusiones, otros estudios demostraron que la tesis de las playas marinas era insostenible. Se acabó por probar que se trataba de marcas dejadas por un lago glacial ${ }^{29} \mathrm{La}$ situación fue particularmente embarazosa para Darwin, pues un año antes él había asumido el cargo de secretario general de la Geological Society, cargo que ocupó durante tres años y, que debería ayudar a consolidar su reputación como científico. Definitivamente, en este sentido, el caso no fue estimulante. ${ }^{30}$

Para Huxley y Kettlewell el caso de las líneas paralelas de Glen Roy servirían para enseñar una lección a Darwin. En sus propias palabras;

él nunca mas sacaría conclusiones antes de ponerlas a prueba frente a un vasto conjunto de hechos obtenidos con ese fin específico. ${ }^{31}$

Dentro de este cuadro, es muy difícil que algo errado fuera publicado por Darwin veinte años después en el Origen de las Especies o en cualquier otro trabajo subsiguiente.

Junto con la imagen de infalibilidad de la ciencia y del científico, el libro de Huxley y Kettlewell presenta una "imagen franciscana" de Darwin, que se identifica con un perfil trazado desde Francis Darwin (por eso llamada "franciscana"). Un científico inmune al medio social en el cual vivía, sin hipótesis de trabajo previamente establecidas, con un único objetivo central en sus investigaciones, en toda su trayectoria como científico. El relato de su vida aparece lleno de hechos episódicos, estrictamente personales, y detalles muy particulares. La dimensión histórica y social inherente a la existencia de cualquier persona es simplemente enmascarada. Jon Hodge escribió un excelente artículo de revisión donde discute dicha visión franciscana sobre Darwin y propone una visión alternativa (Hodge 1990). ${ }^{32}$

¿Cuál es la influencia que esas ideas ejercen sobre nuestros estudiantes hoy día, después de veinte años de su publicación?. Es evidente que esta pregunta es de difícil respuesta, pero es posible encontrar alusiones de esas idea en recientes publicaciones dirigidas al gran publico. Al inicio del año 1988 fue publicado el trabajo "Darwin: la evolución de un hombre" 33 donde se observa con claridad una imagen; él es presentado como una persona con características personales distintivas de los grandes científicos, excepto durante la infancia. El culto a la personalidad de Darwin, característica de la aproximación de Huxley y Kettlewell, también se encuentra en todo este trabajo. Por ejemplo, en uno de sus títulos "Siempre al margen de la política”, que se resume en la cita que sigue:

Karl Marx, que estaba empeñado como nunca en la construcción de sus doctrinas politicas, económicas y filosóficas, vislumbró (una supuesta sólida convicción materialista) e intentó, en más de una oportunidad, aproximarse a él con la idea de cooptarlo para su causa. Darwin siempre se esquivó y cortésmente rechazó hasta la dedicatoria que Marx le pretendió hacer, del segundo volumen de El Capital. ${ }^{34}$

\footnotetext{
${ }^{29}$ Rudwick, 1974 (citado).

${ }^{30}$ Se especula que Darwin no recibió el título de "Sir", el cual fue concedido a Lyell, en parte por causa de este episodio.

${ }^{31}$ Huxley and Kettlewell, 1975. Nótese que aqui el Darwinismo se asume como una forma de resolver problemas, aspecto señalado por Greene (1981).

${ }_{32}$ Hodge, M.S.J. Origins and Species before and after de Darwin, IN Olby, R. C, G.N. Cantor, Routlege, (1990).

${ }_{33}$ Godoy, Norton. Darwin: a evolução de um homen. Revista superinteressante, Maio:41-51 (1988).

${ }^{34}$ Godoy, 1988
} 
Estas líneas aparecen, después de haberse afirmado, que la autoría de la utilización de las ideas de Darwin en el campo político fuera iniciativa de Herbert Spencer, quien acuñò la frase "sobrevivencia del más apto" con la intención de "utilizar las leyes de la Biología enunciadas por Darwin para explicar y justificar la sociedad estratificada producida, en esa época, por el capitalismo industrial" ${ }^{35}$ Claramente se pretende afirmar que la Social Statics (1850) es una obra posterior al Origen de las Especies (1859). Como eso no es verdad, la tesis de este trabajo terminó siendo débil.

La salud de Darwin también mereció una aclaración, se insistió mucho en la adquisición del Mal de Chagas en Brasil. La propia manera como se propone la argumentación muestra ambigüedad y medias verdades: "Se sospecha que en Brasil haya adquirido el Mal de Chagas(...)”. Esta frase da la impresión que la duda se refiere al sitio donde ésta fue adquirida y no al tipo de enfermedad que padecía. ¿Por qué insistir en la idea de que Darwin era un pobre hombre abatido por ese tipo de dolencia?. Afirmar que él sufría de disturbios psicológicos parece ser una afirmación muy atrevida que afecta la imagen que se quería instituir.

Otros pasajes, del trabajo que estamos citando, pretenden construir una imagen de un hombre bondadoso, inteligente y perseverante. Un hombre combatido por todos, a pesar de ser un liberal que detestaba la esclavitud. Thomas Huxley, que aparece en una foto en cuya leyenda dice "El más delicado y competente defensor de Darwin", "queda mudo". Como lo mostró Robert Maxwell Young ${ }^{36}$, las justificaciones a favor de la abolición de la esclavitud, serían contraproducentes para seducir al lector y poco convincentes para sostener dicha idea de la personalidad del científico.

Una gran contribución habría sido la de controvertir las concepciones de Lamarck, que erró al afirmar que "la evolución ocurre porque las características adquiridas por los animales, son transmitidas a los descendientes". Sin embargo, las obras de popularización científica, mas que permitir una comprensión de las diferencias entre Darwin y Lamarck, han logrado, por el contrario, acrecentar los obstáculos, la confusión y los malos entendidos respecto de las teorías de la herencia que se estaban discutiendo en esa época.

Cuando Darwin, aún en los bancos escolares, leía las obras de teología natural de Paley, que presentaba el mundo natural como un gran conjunto de engranajes ordenados por la acción de un relojero divino, jamás se hubiera imaginado que su respuesta a tal concepción, posteriormente, quedaría reducida a simples embates entre la selección natural y la herencia de los caracteres adquiridos. Mas, las obras de popularización científica lo lograron. Ya sea, distorsionando u omitiendo datos, o convirtiéndolo en un relojero ciego. Ésta última tendencia subsiste en la actualidad, situación aún, muy lejos de ser modificada.

\section{El reloj de Richard Dawkins no adelanta}

La tan elogiada obra de Richard Dawkins The blind watchmaker ${ }^{37}$ es asumida por el autor, dicho en sus propias palabras, como "una defensa apasionada del darwinismo"; una vez que éste ha sido objeto de críticas tanto emocionales como poco pertinentes.

\footnotetext{
${ }^{35}$ Godoy, 1988

${ }^{36}$ Los ensayos de Huxley son también transcritos de su obra de 1865 llamada "Emancipation-Black and White", donde se pueden encontrar argumentos muy originales a favor de la abolición de la esclavitud (el fragmento parece ser una referencia a la guerra de secesión Norteamericana). Decía Huxley que nadie dudaba que las capacidades del hombre blanco "con mayor cerebro y menor mandibula", superan las de los negros. Entonces, él decía que no habia necesidad de oponerse a su libertad, ya que permanecerán sometidos a la superioridad del blanco, por sus propias características naturales. Ellos no podrán quejarse de su condición social, una vez que toda responsabilidad, en adelante será una cuestión a resolver entre ellos y la naturaleza'.

37 Dawkins, R. The blind watchmaker. Londres, Penguin Books, (1988). La edición brasileña demoró 13 años a salir: "O Relojoeiro Cego: A Teoria da Evolução contra o Desígnio Divino" (Trad. de Laura Teixeira Motta), São Paulo: Companhia das Letras, 2001.
} 
Al contrario de la obra de Huxley y Kettwell, ésta no posee un tono biográfico e individualista, mas bien se trata de seducir al lector hacia las ideas, buscando que ellas sean convincentes y, no hacia la admiración de la personalidad del científico o del hombre. El autor centra sus esfuerzos en los argumentos que pueden ser utilizados para atacar el darwinismo. Su estrategia consiste en presentar una constelación de ejemplos bastante creativos, capaces de ilustrar sus puntos de vista en defensa de las enseñanzas de Darwin.

Su lenguaje es simultáneamente claro, simple y preciso. Sin abusar del lector lego evita las súper-simplificaciones. Es así como, él es capaz de hablar de ácidos nucleicos en un tono simple y claro, describiendo el ambiente bucólico rodea su casa.("la arboleda diseminando sus semillas en un riachuelo de aguas limpias y tranquilas en frente a mi casa...”).

Un cierto abuso, por más elegante, erudito y sofisticado que sea, no pasa desapercibido cuando Dawkins se propone hablar del efecto acumulativo de la selección natural. Una antigua crítica decía que la probabilidad de ocurrencia de la evolución podría ser comparada con la probabilidad de que un mono produjera un poema de Shapeskeare sentado frente a una máquina de escribir digitando al azar.

Dawkins reproduce un diálogo Shakesperiano entre Hamlet y Polónio, al observar las nubes con sus formas abstractas:

"Methinks it is like a weasel", exclama Hamlet. Digitar al azar en una máquina de escribir con los ojos vendados y reproducir una obra literaria de Shapeskeare es solamente una cuestión de suerte; es saber lidiar con lo inmensamente improbable. La probabilidad, para lograr realizar los 28 toques correctos de la frase de Hamlet, es de $(1 / 27)^{28}$ !!

Un evento tan improbable es prácticamente imposible. Sin embargo Dawkins afirma - es aquí en donde comienza el abuso - se puede acudir a la selección acumulativa, para aumentar las probabilidades de ocurrencia. Dawkins utiliza un programa de ordenador que sortea letras al azar y mantiene aquellas que coinciden con las de la frase. Cada sorteo representa una generación de letras. De esta manera, el ordenador escribió "Y YVWQKSPFTWSHLIKEFV HQYSPY”. En la 30a generación ya el programa produjo la oración: "METHINKS IT ISSLIKE A WEFSEY", y finalmente en la $64^{a}$ llegó a la frase Shakesperiana. No obstante este virtuosismo digitalizado, las semejanzas con el mundo biológico son muy flacas. Aunque, sea una forma muy interesante de jugar con probabilidades, transformando opciones muy remotas en algo prácticamente infalible, consolida conceptos de selección natural y diseño biológico muy discutibles.

Cierta vez Wickramansighe, conocido astrónomo, colaborador de Sir Fred Hoyle, escribió que la probabilidad de ocurrir espontáneamente la vida, por una única vez en diez billones de años, sería igual a la probabilidad de formar un avión nuevo después de un ventarrón sobre un depósito de aviones viejos ${ }^{38}$. Lo que encontramos de común en las metáforas, aeronáuticas o digitales de Dawkins y Wickramansighe, es la imagen de naturaleza que transmiten. Ella parece estar como en búsqueda de algo pre-establecido. En el caso de la frase perseguida por el ordenador ella no puede ser modificada con el tiempo cuando suceden situaciones imprevistas; tampoco se podrán producir versos García-lorquianos o sones rituales de aborígenes de Zimbabwe. De la misma forma, si un ventarrón quisiera corroborar los modelos producidos por el intelecto humano, sólo podrá producir un ejemplar de avión absolutamente igual, a aquel, sobre el cual está soplando. En el caso, en que fuese a producir una obra de arte moderna, por ejemplo, le será completamente inútil.

Es interesante notar, como los dos ejemplos se valen de la misma imagen de naturaleza, absolutamente antropocéntrica - por no decir etno-céntrica - conciliando puntos

${ }^{38}$ Wickramasinghe, Nalin Chandra. E se a vida veio do espaço? Correio da Unesco 10 (7): 36-8 (Julho/1982). 
diametralmente diferentes. Mientras Dawkins nos quiere probar, que algo es absolutamente imposible de no suceder, justamente Wickramansighe quiere llegar a la conclusión contraria.

El libro de Stephen Jay Gould, dedicado al análisis de la historia de los fósiles de roca foleada de Burgess en la Columbia Británica (Canadá) ${ }^{39}$, muestra claramente que no existen patrones pre-definidos en la naturaleza. Los propios nombres que estos animales reciben, de cierta forma muestran el asombro de los zoólogos frente a ellos: Anomalocaris, Hallucigenia, Opabinia $^{40}$, etc. Es verdad que estos patrones pre-establecidos pueden existir, pero ciertamente no están en la naturaleza, sino en la mente de quien la observa.

Cuando esta idea de selección se hizo presente en las salas académicas, aún Darwin utilizaba su primera cuchilla de afeitar, ella ya era criticada por su poca potencialidad creativa. Era difícil entender cómo, con sólo la simple eliminación de un grupo de individuos de una especie, se originan modificaciones cualitativas en ésta. Por lo tanto, no es una cuestión de azar, que Dawkins enfrente este asunto tomando, precisamente el ejemplo del ojo humano, utilizado hace más de cien años para rebatir el poder creativo de la selección natural. Dawkins seduce al lector con pasajes en los que muestra, que si bien es cierto existen patrones de organización de la vida cambiantes en el tiempo, también es verdad, que su posible variación no es infinita. El ejemplo del ojo humano, es uno de ellos, una vez que ciertos moluscos: los cefalópodos, llegaron a soluciones muy parecidas y bastante eficientes. Lo original y realmente fascinante de Dawkins, fue su búsqueda en la historia, de la investigación de la ecolocalización de los murciélagos y de la invención del radar, por parte de los ingleses, un poco antes de la segunda guerra mundial. El paralelo encontrado fue tan grande, que hasta se pensó que los zoólogos habían violado secretos militares. No se podía admitir, que simples murciélagos ya dispusiesen de modernos radares, antes de la RAF!

Después de analizar aspectos sobre el almacenamiento de información, el carácter constructivo de la evolución, examinar muy superficialmente el equilibrio puntuado y de abordar las genealogías en la vida, Dawkins expone toda su ardiente pasión por el darvinismo, en el último capítulo llamado "los rivales de la muerte". Cuando todo indicaba una exposición innovadora, hasta por la sofisticación tecnológica de los ejemplos, Dawkins intenta probar la confiabilidad de la teoría utilizando el lamarckismo como contrapunto. Dawkins entiende, el lamarckismo, fundamentalmente como la creencia en la transmisión de los caracteres adquiridos. Los rivales de la muerte, son nada menos, que Darwin y Lamarck. Restando toda la originalidad y altura a los planteamientos, se instaura la versión maniqueísta del "errado" lamarckismo y el "acertado" darwinismo, el cual, todavía, no conocía los trabajos de Mendel. No es difícil plantear una duda en la interpretación de Dawkins. Sin embargo, en la Sala de Manuscritos de la Universidad de Cambridge se encuentra una separata que describe los trabajos de hibridismo de Mendel. En la última hoja de la separata Darwin escribió:

\section{Si Hoffman supone que Ph. multiflorus (que puede decirse de passagen e sinonimia de Ph. coc- cineus de Lamarck) es fértil en Alemania donde no existen insectos //o el clima afecta la planta, o que yo no creo, o que dos especies son confundidas con el mismo nombre. \\ C. Darwin}

\section{Hoffmann describe Ph multiflorus ¿cómo una planta alta con flores escarlata??}

\footnotetext{
${ }^{39}$ Gould, S. J. Wonderful Life. New York, Norton, (1989).

${ }^{40}$ Este genero fue tomado como Arthopoda por más de 50 años, hasta probar que no habia apéndices articulados en los fósiles. 
Mi apreciado $F^{41}$. aqui está un trabajo horrible que yo te imploro que sea hecho muy rápido, i e, llegar a las conclusiones de Hoffmann sobre la fertilización de Phaseolous. p. 47-80. El da un resumen que tal vez sea suficiente. Phaseolous multiflorus, o la rastejante escarlata, es una planta con la cual ya realice experiencias y mis resultados (ie, no puede ser fértil sin insectos) han sido confirmados desde entonces por Olge \& Belt. Yo tengo la certeza de que Ph vulgaris es plenamente auto-fértil. ${ }^{42}$

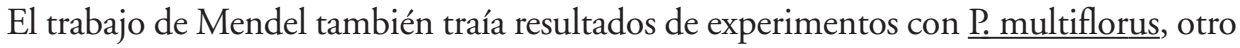
motivo de atención para Darwin.

Por lo tanto, la información de que el trabajo de Mendel, no pasó por las manos de Darwin, es rigurosamente incorrecta. Como afirmó Sir Ronald Fisher, "Darwin estaba buscando otra teoría”3. Aunque Mendel hubiese sido el párroco de la iglesia de St. Mary, en Downe, Darwin no habría obtenido ningún beneficio con sus resultados; ya que por aquella época Darwin realizaba experimentos con los mismos guisantes, a pesar del mayor número y mejores condiciones de experimentación.

La idea de que la herencia de los caracteres adquiridos no tuvo ninguna importancia en sus teorías, como afirmó Dawnkins, también es equivocada. Puesto que todas las evidencias disponibles van, exactamente, en dirección opuesta. Poco antes de lanzar The variation of Animals and Plants under Domestication, en 1867 Darwin decía en una carta a Lyell $^{44}$ que la Pangénesis tenía de 26 a 27 años de edad. En otras palabras, ella era casi contemporánea de la propia selección natural (adoptándose como referencia septiembre de 1838 fecha en la cual Darwin leería a Malthus). Así cuando Darwin escribe el primer borrador de las teorías evolutivas, en 1842, ya tenía en mente "una hipótesis provisoria" sobre como las características pasan de padres a hijos. Los innumerables trozos del "Origen...", en los cuales Darwin se refiere a la herencia de los caracteres adquiridos, son indicaciones claras de que sus ideas sobre la herencia hacían parte de su teoría de la evolución.

Es bien sabido que el libro The variation of Animals and Plants under Domestication era para Darwin, más importante científicamente que el Origen de las Especies. Este último fue escrito de prisa, sin referencias bibliográficas, compilando un texto más largo, pero incompleto (que vendría a ser publicado apenas en 1975 por Robert Stauffer, con el título Natural Selection (ya citado). Los dos primeros capítulos de esto largo manuscrito fueron separados, pues la intención de Darwin era desarrollarlos adecuadamente. Ellos trataban, justamente, sobre variaciones de plantas y animales domesticados. El "Variations..." contenía justamente su más importante teoría, como ya dijimos; en palabras de Lyell, el 22 agosto 1867, que se trataba de una teoría de "26 o 27 años de edad" 45 , sobre sus visiones respecto la herencia. Para muchos (p. ex. Darlington, 1960 y Eisley, 1961), Darwin creía en la selección natural como principal motor de la evolución, pero no podría continuar sosteniendo está hipótesis hasta no tener una explicación aceptable del origen de las variaciones. Este era, precisamente el objetivo de su libro "Variation...". Escribió M. Ghiselin (1984):

Gran parte del orden dado por la teoría de la selección natural fue consistente con el actual mecanismo de cambio; Darwin también superó las dificultades teóricas mezcladas con la herencia, una

\footnotetext{
${ }^{41}$ Inicial de Francis, su hijo que por esa época tenía 21 años, que lo ayudaba en sus experimentos en su casa de Dawne ${ }^{42}$ En el original "scarlet runnig".

${ }^{43}$ Sir Rowland Aylmer Fisher and William Bateson, Gregor Mendel 1965, (citado)

${ }^{44}$ Darwin. Lyell, 22/8/1867. In Darwin, F (ed) The life and letters of Charles Darwin, J Murray, Londres, Pág.255 (vol II) (1959).

${ }_{45}$ Algunos historiadores de la ciencia como Jonathan Hodge (comunicación personal a N. Bizzo) creen que Darwin ha exagerado cuando escribió la carta a Lyell. Nosotros no compartimos esta idea.
} 
El mito darwinista en el aula...

vez que culminó una serie de investigaciones. Estos estudios se realizaron con plantas y animales salvajes y domésticos. Sus ideas están resumidas brevemente en The Origin of Species y en The Descent of Man y se desarrollaron extensamente en The Variation of Animals and Plants under Domestication.

En la presentación del libro, Darwin se disculpa, diciendo que la demora en publicarlo se debió a sus problemas de salud; como lo diría en la introducción de The variation...

Para cualquiera que haya leido atentamente el 'Origen de las Especies' esta introducción le será superflua. Como afirmé en aquel trabajo, yo debería publicar en breve los hechos en los cuales las conclusiones se apoyan y aprovecho para pedir permiso y disculparme por la gran demora en publicar este trabajo, que se debió a mis precarias condiciones de salud en este periodo. ${ }^{46}$

Las ideas de Darwin sobre la herencia eran hasta cierto punto sofisticadas, pero no consiguieron prever nuevas líneas de investigación, lo que se esperaría de una teoría revolucionaria, en términos kuhnianos. Pero, cabe ahora analizar la afirmación de Dawkins que la pangénesis "no hacia parte de su teoría evolutiva".

La importancia relativa del capítulo sobre pangénesis puede ser valorada a partir de su correspondencia con Wallace, quien le escribió, que al recibir el libro había leído ávidamente el capítulo de la pangénesis. La recomendación que Darwin hizo a Hooker ${ }^{47}$ también es bastante clara: debería ir directo al último capítulo, exactamente el de la pangénesis, una teoría casi tan vieja como la propia selección natural. También es verdad que Huxley desaprobó la "hipótesis provisoria" de inmediato, pero él es reiteradamente reconocido como el discípulo más próximo de Darwin que "jamás entendió sus ideas". ¿Cómo puede ser dicho, entonces, que ella "no era parte de su teoría de la evolución?". En verdad, tal vez lo que Dawkins habría querido decir, es que ella no hace parte de las teorías que los científicos reconocen hoy día, lo que es completamente diferente y explica la falta de interés por su conocimiento.

Al respecto, cabe recordar la conocida versión que Darwin se habría inclinado en dirección a la herencia de caracteres adquiridos después de la crítica hecha a su modelo de "mezcla de caracteres" ("blending inheritance"). Como vimos, la creencia en la pangénesis era anterior a la crítica que Fleeming Jenkin publicó en Julio de 1867. En esta fecha, además, el libro "Variation..." y la "teoría provisoria" estaban siendo impresas, lo que demuestra la falacia del argumento. ${ }^{48}$

Pero, la gran manipulación histórica será realizada por Dawkins al relacionar el "pensamiento no-darwinista", en el sentido de no ser correcto históricamente, al pensamiento "de izquierda". Esta componenda fue hecha en el pasado, de forma no tan explícita, por Edward Wilson y su co-autor Lumsden en Genes, Mind and Culture (1981), cuando igualaron el marxismo al lamarckismo y el capitalismo al darwinismo. ${ }^{49}$ Dawkins parece ser aún más ambicioso, en este trecho:

La apelación emocional al lamarckismo y la hostilidad al darwinismo que lo acompañan, ha sido a lo largo del tiempo siniestro, mediante la construcción de ideologias poderosas utilizadas como alternativas a la razón. En efecto, T. D. Lisenko era un agricultor de segunda linea, sin ninguna distinción mas allá del mundo de la politica. Su fanatismo anti-mendeliano, y su ardorosa y dogmática creencia en la herencia de los caracteres adquiridos, habrian pasado desapercibidos en la mayoria de los paises civilizados. Desafortunadamente, el vivia en un pais donde la ideologia

\footnotetext{
${ }^{46}$ Darwin, C. The variation of Animals and Plants under Domestication, J. Murray, London, II vols, (1868), Pág.2 (I).

${ }^{47}$ Carta de Darwin para Hooker, 17/11/1867, in Darwin, F. (1959), Pág.257 (vol II).

${ }^{48}$ Vorzimmer, P. Charles Darwin and Blending Inheritance. Isis, Chicago 54: 371-90, (1963).
} 
importaba más que la verdad cientifica. El 1940 él fue designado director del instituto de genética de la Unión Soviética, y se volviéndose inmensamente influyente. Sus creencias fantasiosas se constituyeron en las únicas que podían ser enseñadas en las escuelas soviéticas durante una generación. Incalculables perjuicios fueron causados a la agricultura soviética. Muchos genetistas soviéticos de primera linea fueron sacados, exiliados o detenidos. Por ejemplo, N.I.Vavilov, un genetista de reputación mundial murió de desnutrición en una prisión, después de un prolongado juicio, donde fue acusado de crimines falsos como el de espiar para los británicos. ${ }^{50}$

La relación entre el "errado" lamarckismo con el régimen soviético, en su fase más execrable, queda clara. Como en la alegoría de la dedicatoria de El Capital, la precisión de los hechos parece no ser muy importante. Aquí se observa una alianza Lamarck-Lisenko que tampoco sobresale por la originalidad. Reducir las ideas de Lisenko a la creencia de los caracteres adquiridos es una distorsión solo comparable a la afirmación de que la agricultura soviética haya sido arruinada por las ideas evolucionistas de la era stalinista. En verdad, las ideas de Lisenko procuraban enfrentar la dicotomía soma-germen de Weismann, que había radicalizado la idea de selección natural. Pero lo hacia a la luz de la dialéctica institucional, lo que le confería legitimidad. Por otra parte, esto no trajo ninguna consecuencia trágica para la agricultura soviética.

Las razones por las cuales tal relación marxismo x capitalismo fue establecida queda incierta y estudios posteriores, desde perspectivas sociológicas, podrán lanzar alguna luz sobre tal hecho.

\footnotetext{
49 Véase en especial el capitulo "La explicación de la Historia", en Wilson y Lumsden, (1981).

${ }^{50}$ Dawkins, 1988 (citado). pág. 292. 


\section{Referências}

BIZZO, N. M. V. Ensino de evolução e história do darwinismo. 1991. Tese (Doutorado)-Faculdade de Educação da Universidade de São Paulo, São Paulo, 1991.

. From down house landlord to brazilian high school students: what has happened to evolutionay knowledge on the way? Journal of Research in Science Teaching, New York, v. 31, n. 5, p. 537-556, 1994.

1997.

Darwin e o mundo acadêmico I: aproximações baconianas. Epistéme, Tubarão, v. 3, n. 2, p. 73-104,

. Darwin: do telhado das Américas à teoria da evolução. São Paulo: Odysseus, 2002.

COLP JUNIOR, R. The contacs of Chales Darwin with Edward Aveling and Karl Marx. Annals of Science, London, v. 33, p. 387-394, 1976.

. The contacs between Karl Marx y Chales Darwin. Journal of the History of Ideas, Philadelphia, v. 35, p. 329-338, 1974.

DARLINGTON, C. D., Darwin's place in history. Oxford: Blackwell, 1960.

DARWIN, C. Variations and plants under domestication. London: John Murray, 1868.

DARWIN, C. R. Observations on the parallel roads of Glen Roy, and of other parts of Lochaber, with an attempt to prove that they are of marine origen. Philosophical Transactions of the Royal Society of London, London, v. 129, p. 39-81, 1839.

On the connection of certain volcanic phenomena and on formation of mountain chains and volcanos as the effects of continental elevations. Proccedings of the Geological Society of London, London, v. 2, n. 56, p. 654-660, 1838.

DARWIN, C. D. The origin of species by means of natural selection or the preservation of favored races in the struggle for life. London: John Murray, 1859. Disponível em:

http://pages.britishlibrary.net/charles.darwin/texts/origin1859/origin09.html. Acesso em: 25/01/2005

The origin of species by means of natural selection or the preservation of favored races in the struggle for life. 6. ed. [S.1.]: Lightbinders, 1997. CD-ROM.

DARWIN, F. (Ed.). The life and letters of Charles Darwin. Londres, John Murray, 1959.

DARWIN-LYELL, D. Darwin papers, manuscripts room. Cambridge: Cambridge University Library, 1860.

DAWKINS, R. The blind watchmaker. Londres: Penguin Books, 1988.

EISLEY, L. Darwin's Century: evolution and the men who discovered it. New York: Anchor, 1961. 
FAY, M. A. Did Marx offer to dedicate capital to Darwin? Journal of History, v. 39, p. 133-46, 1979.

FREUER, L. Is the "Darwin-Marx" correspondence authentic? Annals of Science, London, v. 32, p. 1-12, 1975.

GHISELIN, M. T. The Triumph of the darwinian method. 2nd ed. Chicago: University of Chicago Press, 1984.

GODOY, N. Darwin: a evolução de um homem. Superinteressante, São Paulo, no 5, p. 41-51, maio, 1988.

GOULD, S. J. Wonderful life. New York: Norton, 1989.

HODGE, M. S. J. Origins and Species before and after de Darwin. In: OLBY, R. C. et al. (Ed.). Companion to the history of modern science. New York: Routledge, 1990.

HUXLEY, J.; KETTLEWELL, H. B. D. Charles Darwin and his world. [S.1.]: Book Club Associates, 1975.

LUMSDEN, C. J.; WILSON, E . O. Genes, mind and culture. Cambridge: Harvard University Press, 1981.

PECKHAN, M. The origin of species by Charles Darwin: a variorum text. Philadelphia: University of Pennsylvania Press, 1959.

RUDWICK, M. Darwin and Glen Roy: a "great failure" in scientific method? Studies in the History and Philosophy of Science, v. 5, p. 97-185, 1974.

STAUFFER, R. C. Charles Darwin's natural selection: being the second part of his big 'species book written from 1856 to 1858. Cambridge: Cambridge University Press, 1975.

VORZIMMER, P. Charles Darwin and Blending Inheritance. Isis, Chicago, v. 54, p. 371-90, 1963.

WICKRAMASINGHE, N. C. E se a vida veio do espaço? Correio da Unesco, Paris, v.10, n. 7 , p. 36-8, jul.1982. 